\title{
ESTRUCTURA Y EXPLOTACIÓN DE LOS RECURSOS LÍTICOS EN EL SECTOR MERIDIONAL DE LA MESETA CENTRAL DE SANTA CRUZ, ARGENTINA
}

FABIANA SKARBUN"

\section{RESUMEN}

Se busca delinear la estructura de recursos líticos del sector meridional del macizo del Deseado, Santa Cruz, Argentina. Se analiza la disponibilidad y distribución de materias primas, la variabilidad litológica, y las características espaciales de las fuentes. Además, se estudia la relación entre las fuentes y los sitios arqueológicos. Los resultados indican que existe alta disponibilidad y distribución de materias primas silíceas, de calidad regular a muy buena. Suelen aflorar sobre la formación chön aike y se concentran en fuentes de aprovisionamiento que en su mayoría fueron utilizadas como canteras o canteras taller por los grupos que habitaron la región.

PALABRAS CLAVE: materias primas líticas, estrategias de aprovisionamiento, Patagonia.

\section{STRUCTURE AND EXPLOITATION OF LITHIC RESOURCES OF MERIDIONAL SECTOR OF CENTRAL PLATEAU OF SANTA CRUZ, ARGENTINA}

\begin{abstract}
This paper seeks to describe the structure of lithic resources in the meridional area of the Desado massif, in the province of Santa Cruz, Argentina. The availability and distribution of raw materials are analyzed, as well as their lithological variability and the spatial characteristics of the sources. The relationship between the sources and the archaeological sites is also studied. Results show that there is a high availability and distribution of siliceous raw materials. Their quality for knapping ranges from very good to regular. Usually they emerge in the chon aike formation and are gathered in sources which were usually used as quarries or quarries/workshops by the groups which inhabited the region.
\end{abstract}

KEY WORDS: lithic raw material, strategies of acquisition, Patagonian.

\section{INTRODUCCIÓN}

Los artefactos líticos son el resultado de un proceso de producción social y son realizados para trabajar en diferentes ámbitos de consumo de una sociedad. De esta manera, los grupos sociales se

* Facultad de Ciencias Naturales y Museo, Universidad Nacional de La Plata. Museo de Ciencias Naturales, Paseo del Bosque S/N. CONICET. fskarbun@fcnym.unlp.edu.ar 
organizan en función de la práctica de estas tareas, considerando los requerimientos económicos, sociales y ecológicos en donde se desarrollan. Esta organización abarca la selección y obtención de las materias primas, la preparación de los núcleos, la extracción de formas base y la manera en que se diseñan, usan, mantienen y descartan los artefactos (Binford 1979; Koldehoff 1987; Nelson 1991). Así, las fuentes de materias primas se constituyen en el lugar donde se inicia este proceso y están intimamente relacionadas al paisaje donde se realiza el resto de las actividades de manufactura (Ericson 1984). Por lo tanto, es en las canteras donde se comienzan a desplegar las estrategias tecnológicas vinculadas con la producción artefactual. En este sentido, si bien las diferentes morfologías, filos y propiedades materiales necesarias para que los artefactos funcionen adecuadamente en una actividad afectan la selección de las materias primas; la estructura de recursos, considerada en relación con la distribución, disponibilidad y características de las rocas -tamaño, forma y calidad para la talla-, afecta las decisiones sobre qué materiales se van a seleccionar, transportar y cómo va a ser la economía (sensu Franco 2004) de los mismos (Andrefsky 1994; Bamforth 1992). De este modo, la planificación de todo el proceso de producción está vinculada a la forma en que se estructuran regionalmente los recursos (Andrefsky 1994; Bamforth 1992; Ericson 1984; Escola 2004; Franco 2004; Kuhn 1994; Nelson 1991). Esta estructura también influye en la forma en que circulan las materias primas y los grupos humanos en el paisaje.

En este trabajo se busca delinear, de manera integral, la estructura de recursos líticos del sector meridional del Macizo del Deseado, Santa Cruz, Argentina. Esto se lleva a cabo a partir de la evaluación de los resultados de las investigaciones realizadas en la Localidad Arqueológica La María y sectores vecinos. En este sentido, se analiza, la disponibilidad y distribución regional de materias primas, la variabilidad de tipos litológicos inter e intrafuente, la accesibilidad de las fuentes, su localización en el paisaje y su relación espacial con sitios arqueológicos locales. A su vez, se pone en relación esta estructura con las evidencias provenientes de los sitios arqueológicos estudiados hasta el momento en la localidad, esto permite profundizar el conocimiento de las estrategias de selección, aprovisionamiento y economía de las materias primas implementadas por los grupos humanos en el pasado para el área de investigación. La información proveniente de este trabajo se enmarca y articula con los estudios que evalúan la presencia de recursos líticos en el Meseta Central (Ambrústolo 2010; Cattáneo 2002; Franco et al. 2011; Frank et al. 2013; Frank et al. 2007; Hermo 2008; Skarbun 2011; Skarbun \& Páez 2012 , entre otros). Estos, en conjunto, permiten profundizar problemáticas más amplias, vinculadas a la organización de las actividades de producción de artefactos líticos.

\section{TECNOLOGÍA LÍTICA EN LA MESETA CENTRAL}

Las investigaciones arqueológicas realizadas en la Meseta Central de Santa Cruz muestran que las áreas con evidencias de ocupación humana reiterada desde el Pleistoceno final hasta el Holoceno tardío suelen presentar una diversa gama de recursos, entre ellos materias primas líticas de buena a excelente calidad para la talla (Aguerre 2003; Cardich et al. 199394; Cattáneo 2002; Frank et al. 2007; Hermo 2008; Miotti 1998 [1989]; Paunero et al. 2005; Skarbun et al. 2007). El estudio de los paisajes donde se encuentran los sitios arqueológicos Cerro Tres Tetas, Los Toldos, Piedra Museo y el Cañadón de La Primavera, indicaron la existencia de sectores con gran abundancia y amplia disponibilidad de fuentes líticas de sílex, calcedonia, xilópalo y tobas silicificadas. Las mismas pueden localizarse en yacimientos primarios sobre las formaciones Chön Aike, La Matilde, Bajo Pobre y en fuentes o depósitos secundarios (Cardich et al. 1993-94; Cattáneo 2002; Hermo 2008; Mansur-Franchomme 1984; Miotti 1998 [1989]). Esta abundancia y disponibilidad se debe a las características litoestratigráficas de las formaciones geológicas dominantes en el Macizo del Deseado (Panza 1994). Se trata de rocas volcánicas del Jurásico medio superior que presentan dos modas composicionales, las rocas ácidas que conforman el Grupo Bahía Laura y las intermedias a básicas que se agrupan en la Formación Bajo Pobre 
(Guido et al. 2006). Cabe señalar, sin embrago, que la disponibilidad y la distribución de los recursos líticos no es homogénea en todo el paisaje del macizo, los estudios realizados en El Cañadón de La Primavera y en el sur de la ría Deseado (Ambrústolo 2010; Hermo 2008) muestran que la disponibilidad las rocas silíceas es variable en el paisaje. Así, se presentan sectores del macizo con disponibilidad escasa (Franco et al. 2011). En relación con el uso de las materias primas, las investigaciones de los sitios estratigráficos del área evidencian que las rocas locales han sido aprovechadas por los grupos humanos que habitaron la región a lo largo del tiempo. En todos ellos se seleccionaron los recursos líticos que eran más abundantes y en general de excelente a buena calidad para la talla - silices, xilópalos, calcedonias y tobas silicificadas-. No obstante, en menor proporción se utilizó la obsidiana negra, el ópalo, la riolita y los pórfidos (Aguerre 2003; Cardich et al. 199394; Cattáneo 2002; Durán 1990; Hermo 2008; Skarbun 2011, entre otros).

Por otra parte, estos paisajes donde se localizan los sitios, muestran cambios que pudieron haber modificado la disponibilidad de recursos, tanto estacionalmente como a lo largo del tiempo. Uno de los factores más importantes en la configuración de los mismos son los cambios hidrológicos. En este sentido, existe evidencia de una mayor energía de los regímenes hídricos de ríos, arroyos, lagos y lagunas de la Meseta Central durante el Pleistoceno final. Las evidencias sedimentológicas de los sitios Piedra Museo, Los Toldos, Casa del Minero 1, Cueva Túnel, El Ceibo 7, La Mesada y Cerro Bombero manifiestan que para el Episodio Frío Reverso Antártico (ca. 11.000-10.000 años AP) (Hajdas et al. 2003) hubo un mayor caudal en los bajos próximos a estos (Paunero 2009). De este modo, la evidencia sedimentaria del sitio Cueva 2 de Los Toldos, muestra que el arroyo del cañadón tuvo una acción fluvial de alta energía para los primeros indicios de ocupación humana, con una concentración de arena gruesa y arena intercalada en la secuencia (Páez et al. 1999). Esta alta acción fluvial también fue inferida a partir del análisis funcional a altos aumentos de microhuellas del conjunto lítico del sitio (Paunero 2009). Otro factor importante a tener en cuenta son los cambios estacionales, en este sentido, Cattáneo (2002) propone que debe considerarse que la disponibilidad de algunas rocas y la accesibilidad a las fuentes secundarias que se encuentran en bajos o bordes de lagunas pudo modificarse durante los meses invernales de fuertes nevadas debido a la densidad de nieve, la crecida de arroyos, lagunas y zanjones, o aluviones.

\section{CARACTERÍSTICAS DE LA LOCALIDAD ARQUEOLÓGICA LA MARÍA}

La localidad arqueológica La María se encuentra en el sector meridional de la meseta, sus coordenadas geográficas están comprendidas entre $48^{\circ} 24^{\prime} \mathrm{S}$ y $48^{\circ} 35^{\prime} \mathrm{S}$ y $68^{\circ} 47^{\prime} \mathrm{O}$ y $68^{\circ} 56^{\prime}$ $\mathrm{O}$, que se corresponden con un área aproximada de $226 \mathrm{~km}^{2}$. Presenta paisajes diversos como lagunas -algunas temporarias-, cañadones, cuencas sin desagües, zanjones ocupados por arroyos intermitentes y un manto de basalto que corona el norte de la localidad. La topografía posee pequeñas elevaciones de pendientes generalmente suaves; las más abruptas se encuentran asociadas a los paredones de los cañadones y del manto de basalto. Es un paisaje de marcada aridez, con vegetación predominante de estepa subarbustiva.

Los resultados de las investigaciones arqueológicas evidencian que las sociedades pasadas ocuparon este espacio sistemáticamente desde el final del Pleistoceno (ca. $11.000{ }^{14} \mathrm{C}$ años AP) (Tabla 1). Así, a lo largo del tiempo, se utilizaron los paisajes con una intensidad $y$ recurrencia variable, según las posibilidades que ofrecían de reparo y recursos. En este contexto, fueron aprovechados de manera redundante a lo largo del tiempo los espacios reparados como cuevas, aleros y abrigos (Paunero 2009).

Entre los sitios arqueológicos en estudio, reparados y al aire libre, se encuentran Casa del Minero 1 (CDM1), Cueva Túnel (CT), La Mesada (LM), Cañadón Negro (CN) y Puesto el Frío (PF) (Fig. 1). Los mismos muestran diversidad funcional, con procesamiento y consumo de fauna extinta y actual, actividades de manufactura de herramientas líticas y óseas, y la producción de arte rupestre (Paunero et al. 2005). 


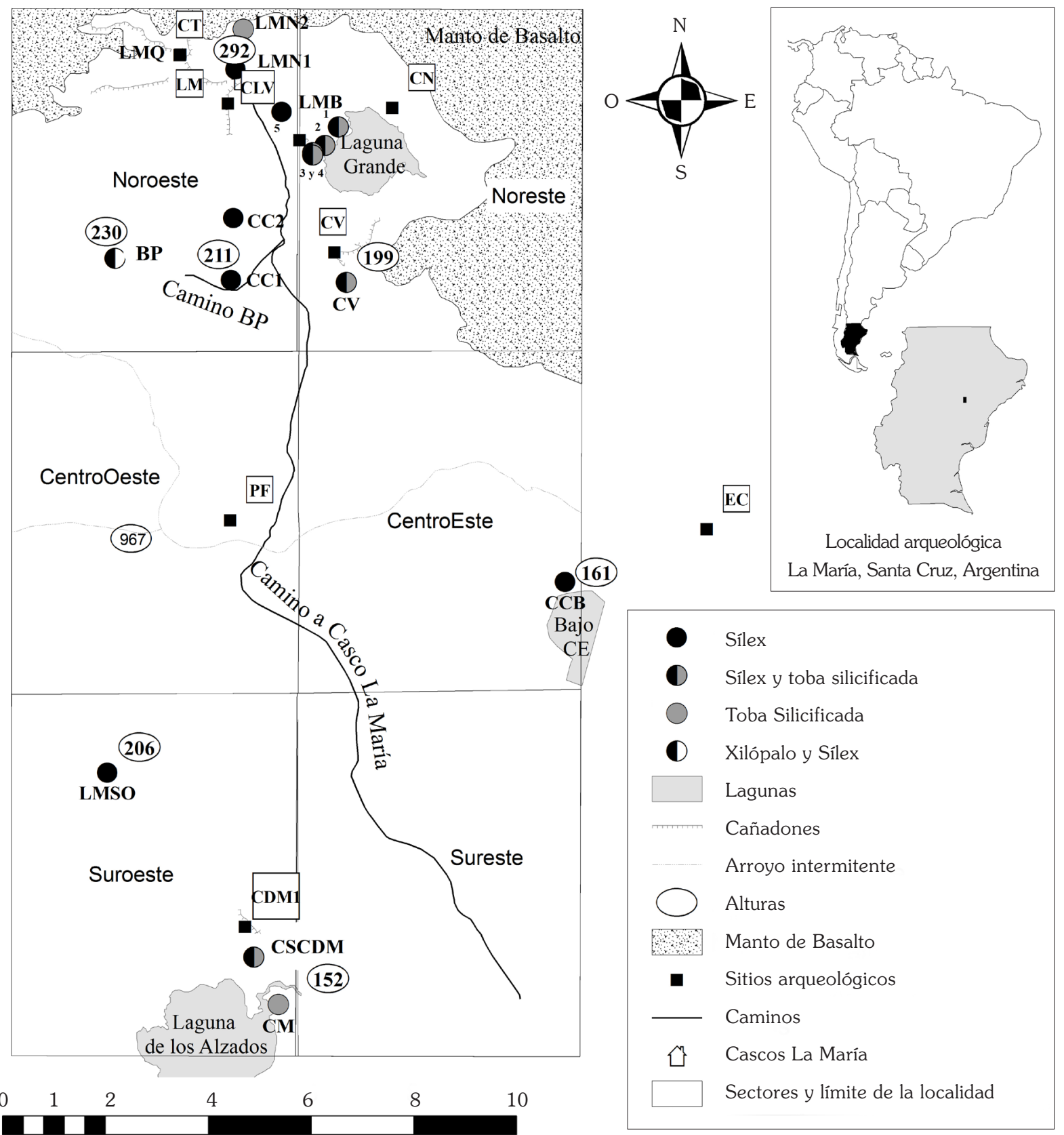

Fig. 1. Localización de las fuentes en el paisaje local.

Estrategias tecnológicas y materias primas

Las evidencias provenientes de los sitios estratificados de la localidad muestran que las estrategias de producción de artefactos presentan variabilidad temporal y espacial. Estas fueron analizadas detalladamente en distintos trabajos publicados sobre el tema (Cueto 2013; Cueto \& Castro 2012; Frank 2011, 2012; Skarbun 2009, 2011, 2012; Skarbun et al. 2013; Skarbun et al. 2007). Por lo tanto, en esta sección se realizará un resumen de los aspectos más relevantes para la compresión de las estrategias discutidas en este trabajo. 
Tabla 1. Fechados radiocarbónicos de los componentes analizados en el trabajo.

\begin{tabular}{|c|c|c|c|c|}
\hline & \multicolumn{2}{|c|}{ CUEVA TÚNEL } & LA MESADA & CASA DEL MINERO 1 \\
\hline Siglo XX & & & & Unidad 1 \\
\hline $\begin{array}{l}\text { Holoceno } \\
\text { Tardío }\end{array}$ & & & & Unidad 2 \\
\hline \multirow{2}{*}{$\begin{array}{l}\text { Holoceno } \\
\text { Medio }\end{array}$} & \multicolumn{2}{|c|}{$\begin{array}{l}\text { Unidad } 4 \\
\text { AA81417: } 4.177 \pm 43 \text { años }{ }^{14} \mathrm{C} \text { AP }\end{array}$} & $\begin{array}{l}\text { Unidad } 5 b \\
\text { Beta - } 135964: 4.500 \pm \\
40 \text { años }{ }^{14} \mathrm{C} \text { AP }\end{array}$ & Unidad 3 A \\
\hline & \multicolumn{2}{|c|}{$\begin{array}{l}\text { Unidad } 5 \\
\text { AA81423: } 5.577 \pm 44 \text { años }{ }^{14} \mathrm{C} \text { AP }\end{array}$} & Unidad 6 & $\begin{array}{l}\text { LP-1552: } 5.190 \pm 80 \text { anos }{ }^{14} \mathrm{C} \\
\text { AP }\end{array}$ \\
\hline $\begin{array}{l}\text { Holoceno } \\
\text { Temprano }\end{array}$ & & & $\begin{array}{l}\text { Unidad } 8 \\
\text { Beta - 135963: } 9090 \pm \\
40 \text { años }{ }^{14} \text { C AP }\end{array}$ & Unidad 3 B \\
\hline \multirow{3}{*}{$\begin{array}{l}\text { Pleistoceno } \\
\text { Final }\end{array}$} & \multirow[b]{3}{*}{ 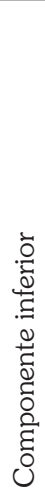 } & $\begin{array}{l}\text { Unidad } 8 \\
\text { LP-1965: } 10.420 \pm 180 \text { años }{ }^{14} \mathrm{C} \\
\text { AP AA82496: } 10.510 \pm 100 \text { años } \\
{ }^{14} \mathrm{C} \text { AP }\end{array}$ & & \multirow[t]{2}{*}{$\begin{array}{l}\text { Unidad } 3 \text { C } \\
\text { AA } 45705: 10.250 \pm 110 \text { años } \\
{ }^{14} \text { C AP }\end{array}$} \\
\hline & & Unidad 9 & & \\
\hline & & $\begin{array}{l}\text { Unidad } 10 \\
\text { AA } 71147: 10.408 \pm 59 \text { años }{ }^{14} \mathrm{C} \\
\text { AP } \\
\text { AA } 71148: 10.400 \pm 100 \text { años } \\
{ }^{14} \text { C AP }\end{array}$ & & $\begin{array}{l}\text { Unidad } 4 \\
\text { AA 37208: } 10.967 \pm 55 \text { años } \\
\text { AP } \\
\text { AA 37207: } 10.999 \pm 55 \text { años } \\
\text { AP }\end{array}$ \\
\hline
\end{tabular}

La materia prima más utilizada en todos los componentes es el sílex, con porcentajes de ca. $70 \%$-, la única excepción a esto la constituye el componente inferior de CT-. En relación con los colores de sílex seleccionados, en los componentes de CDM1 predomina el sílex rojo, siempre mayor al $50 \%$. En el componente inferior de CT el 38,46 $\%$ del sílex es de color gris y el 23,08 \% de color marrón -pardo ocre-. Asimismo, para el sitio LM, en el componente del Holoceno temprano, el sílex marrón se presenta en un $46,67 \%$, mientras que para el Holoceno medio se registró un 36,03 \% de sílex rojo y un 23, 95 \% de marrón (Skarbun 2009, 2011).

En relación a las estrategias implementadas en la producción de artefactos de sílex, existe una tendencia que muestra poca economía y una producción de artefactos fundamentalmente expeditiva (Frank 2011; Skarbun 2011). Los soportes en general no estaban estandarizados y los productos finales fueron frecuentemente lascas retocadas unifaciales con poca regularización del filo. Aunque se desplegaron otras estrategias que involucraron la confección de artefactos con mayor inversión de trabajo en su diseño, las evidencias siguen indicando poca economía su materia prima (Frank 2011; Skarbun 2009, 2011; Skarbun et al. 2007). Un ejemplo es el componente del Holoceno medio de LM. El mismo presenta una recurrencia de diseños tecnológicos laminares estandarizados para los artefactos de sílex. Esta recurrencia se encuentra extendida en otros componentes de la Meseta Central para este bloque temporal (Hermo 2008; Hermo \& Magnin 2012; Paunero et al. 2007)-. Durán (1990) y Hermo (2008) propusieron que podría corresponderse con la forma de prensión, produciéndose el enmangue de los artefactos. Por su parte, Hermo plantea que estos serían el producto de un diseño confiable que permitiría el reemplazo de las piezas en el enmangue (Hermo 
2008). Esta propuesta junto con la presencia en el sitio de un mayor porcentaje de lascas $(65,81$ $\%)$ que de láminas y lascas largas (28,85 \%) entre los productos de talla y de 10 núcleos poliédricos no agotados, utilizados tanto para la obtención de lascas como de láminas (Skarbun, 2009, 2011), permite sostener la idea de una estrategia de poca economía de esta materia prima.

Otra materia prima representada en todos los componentes es el xilópalo. Este se presenta en baja frecuencia, los productos de la talla no superan el $5 \%$ y sólo se registró un artefacto formatizado por componente, o no fue identificado. Solo el componente inferior de CDM1 presenta un porcentaje alto de artefactos formatizados $(36,36$ $\%, 4$ artefactos sobre un total de 11). No obstante, las estrategias de producción no parecen diferir de las del resto de la localidad. En general, no se produjeron actividades de extracción de soportes en los sitios, realizándose sólo los últimos pasos de la producción. Así, habrían ingresado las preformas o los artefactos formatizados ya finalizados. Estos suelen presentar diseños conservados, transportables y versátiles, que involucran mayor inversión de energía en su producción (Skarbun, 2011).

De la misma manera, los productos de talla de calcedonia no superan el $20 \%$ de los materiales registrados y en general sólo se identificó un artefacto formatizado por componente. Sólo en aquellos componentes donde el número de artefactos totales es alto, aumenta la cantidad de artefactos formatizados, aunque los porcentajes en relación al conjunto total siguen siendo bajos. Se identificaron dos estrategias diferentes para esta materia prima. En el componente inferior del Pleistoceno final y en del Holoceno temprano de CDM1 y el componente del Holoceno medio de LM se evidencia economía de esta materias prima. En los componentes de CDM1, ingresaron al sitio piezas en estados avanzados de formatización, realizándose allí los últimos pasos de la secuencia de producción. Asimismo, en el componente medio de LM se identificó un núcleo agotado de calcedonia. Los artefactos fueron confeccionados por retalla parcialmente extendida bifacial $y$ retoque marginal, o por retalla extendida; los diseños son versátiles y probablemente hayan sido transportados. El único artefacto bifacial de este componente fue confeccionado en esta roca. En contraste, en dos de los componentes de CDM1 (en el componente del Pleistoceno final y del Holoceno tardio) se identificaron estrategias que indican poca economía de las materias primas y poca inversión de trabajo en la secuencia de producción de los artefactos (Skarbun, 2011).

También se registraron tobas silicificadas, aunque las mismas se utilizaron escasamente. El porcentaje total para todos los sitios es de 2,91 $\%$, siendo más frecuentes los productos de la talla que los artefactos formatizados. Estos últimos sólo se encuentran en los componentes del Holoceno medio y tardío. En LM se identificó el único núcleo de esta roca. Mientras que posee un porcentaje de productos de talla relativamente alto $(8,95 \%)$ en comparación con el resto de los componentes.

Otras rocas identificadas son el ópalo translúcido, la riolita y la obsidiana negra. La primera se identificó en el componente pleistocénico de CT como materia prima principal (70 \%) para la confección de artefactos formatizados; por sus características litológicas pertenece al grupo Bahía Laura. La riolita, también identificada en este componente, se utilizó para confeccionar un chopping tool. La obsidiana se presenta en porcentajes muy bajos en distintos componentes del Holoceno (Skarbun, 2011).

\section{Características litológicas \\ de las materias primas}

En relación a las características litológicas de las materias primas, en un trabajo previo se realizó la caracterización de 12 segmentos delgados de rocas aptas para la talla provenientes de cinco fuentes de la localidad (Skarbun \& Páez, 2012). Se reconocieron rocas volcánicas lávicas y piroclásticas, cuyo origen está vinculado al hidrotermalismo, así como restos vegetales fósiles. Fueron caracterizadas como pertenecientes a la Provincia Geológica del Macizo del Deseado, específicamente a variaciones litológicas de la formación Chön Aike y La Matilde. Si bien no se pudo establecer una relación directa entre el material lítico arqueológico y los probables afloramientos de procedencia, la comparación de las características litológicas de las muestras evidenció que los materiales se encuentran de manera recurrente 
y ampliamente distribuidos en la localidad. Se observó la existencia de variabilidad intrafuente respecto de los tipos de rocas representados. Así, en CSCDM (Fig. 1) se determinaron lavas e ignimbritas pertenecientes a la formación Chön Aike, rocas piroclásticas retrabajadas posiblemente de la formación La Matilde y ópalos fuertemente teñidos por óxidos de hierro. En BP (Fig. 1) se identificaron restos vegetales fosilizados, lavas, ignimbritas y calcedonias. En CM y LMQ (Fig. 1) sólo se identificó un grupo litológico, calcedonias y ópalos respectivamente. Por otra parte, los análisis mostraron una baja variabilidad interfuente, con una distribución de tipos litológicos amplia, siendo que algunas rocas, como las lavas e ignimbritas, los ópalos y las calcedonias, se encuentran recurrentemente a distancias de más de $10 \mathrm{~km}$.

\section{METODOLOGÍA}

Desde que se comenzó a trabajar en la localidad (Paunero, 2000), se abordó el estudio de los afloramientos y las fuentes de aprovisionamiento de materias primas líticas. Estos trabajos fueron adquiriendo diferentes escalas de análisis en relación con los problemas de investigación planteados y en consideración con la información previa que se poseía sobre el paisaje de la localidad. Así, durante los primeros momentos de investigación, las tareas estuvieron más centradas en el estudio de los sitios estratigráficos y el relevamiento del arte rupestre. Sin embargo, se comenzó con el estudio contextual (sensu Ambrústolo, 2010) de los afloramientos que se iban localizando. Se definió sus tamaños y limites, la variabilidad de tipos de rocas identificadas a nivel macroscópico y el tamaño y forma de su presentación; se geoposicionó su localización y sus rasgos; y se realizó el relevamiento fotográfico. A la vez, se registraron las evidencias de explotación humana, entre ellas la presencia de nódulos con lascados y de restos artefactuales líticos. Esto llevó a la definición de los espacios como canteras y/o canteras taller (Berón et al. 1995). De esta manera, se fue generando un corpus de información sobre la estructura de los recursos líticos que sirvió para comenzar a evaluar las estrategias tecnológicas (Paunero et al. 2005).

A medida que fueron avanzando las investigaciones y se obtuvo mayor detalle sobre esta estructura, se comenzaron a delinear estudios en canteras, reduciendo la escala y ampliando la resolución de análisis (Frank et al. 2013; Frank et al. 2007). Durante estos estudios sistemáticos se geoposicionó la localización, tamaño, límites y las áreas de mayor concentración. Se clasificaron los materiales in situ a partir del muestreo por grillas sin recolección de materiales (Frank et al. 2013; Frank et al. 2007). Estos se enfocaron hacia el análisis de los tipos, atributos y diversidad de restos; se cálculo la frecuencia de tipos de materias primas y de su forma de presentación. Se realizó el análisis tecnomorfológico de los artefactos -utilizando variables acotadas-, y se observó la tipología y diversidad instrumental. También se realizó un relevamiento fotográfico.

Por otra parte, durante los últimos años, se comenzaron a realizar estudios distribucionales, diseñados para muestrear diferentes atributos del paisaje arqueológico, entre ellos las fuentes de materias primas. Se realizaron prospecciones de amplia escala por muestreos sistemáticos probabilísticos (Belardi, 2003), localizándose y geoposicionando nuevos afloramientos. La información recolectada fue el tipo de roca (registrada macroscópicamente) y su forma de presentación. Se definió el tamaño mínimo y/o cualitativo de la fuente, cuando fue posible se registraron las evidencias de explotación y se realizó el relevamiento fotográfico.

Desde los primeros momentos de la investigación también se comenzó a volcar la información en sistemas de información geográfica. Esto permitió armar bases de datos arqueológicas referenciadas a la ubicación de los recursos líticos en el paisaje. En este sentido, se confeccionaron dos mapas, el primero (Fig. 1) se refiere a la localización de las fuentes en el paisaje de la localidad, considerando sus relaciones con los sectores con agua como lagunas, cañadones y arroyos; con rasgos geográficos como elevaciones y el manto de basalto; con rasgos arqueológicos como los sitios superficiales y reparados; y con rasgos actuales como caminos y cascos de estancia. En este mapa se incluye el sitio arqueológico $\mathrm{El}$ Ceibo (EC), que se encuentra por fuera de los límites de la localidad. En el segundo (Fig. 2) se localizaron las fuentes sobre los afloramientos geológicos, en base a la hoja geológica Tres Cerros 


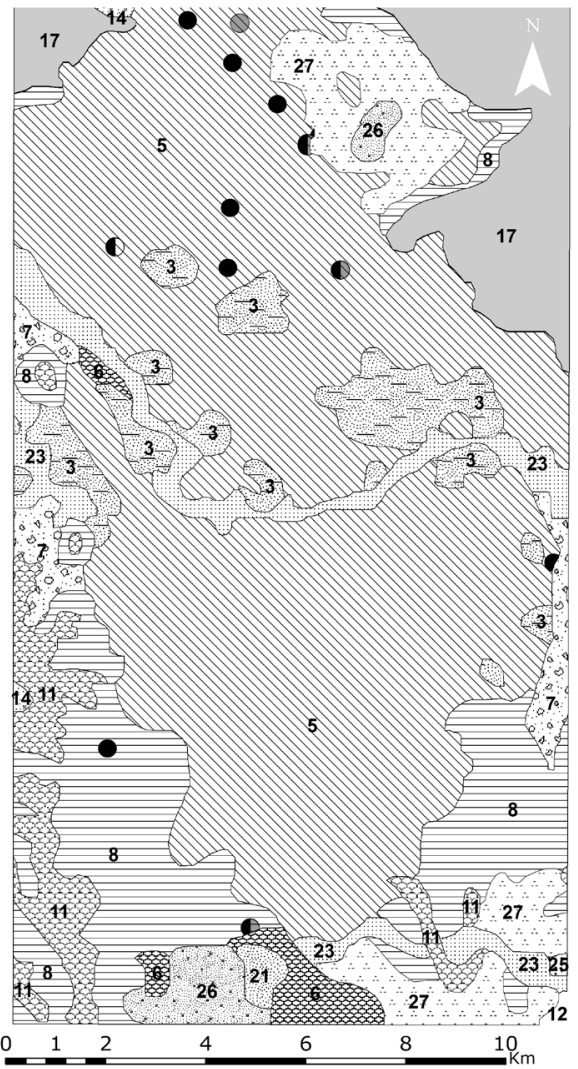

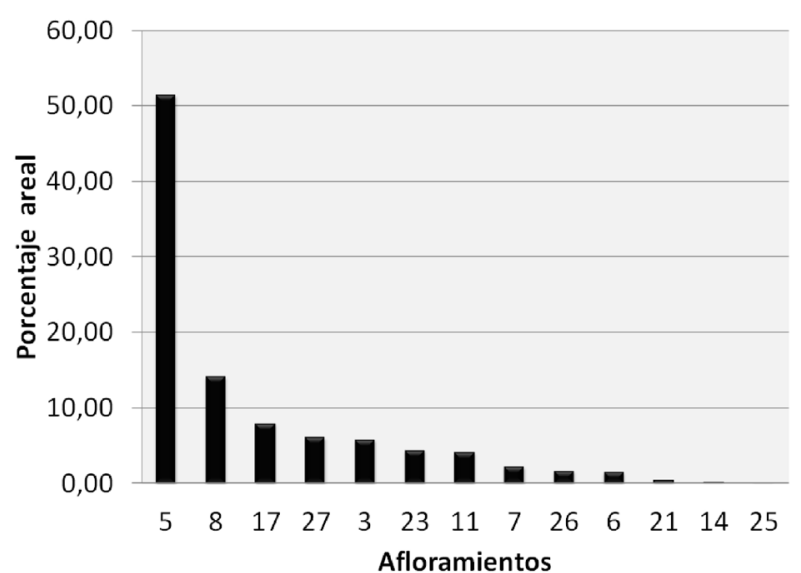

3, Formación Bajo Pobre 5, Formación Chon Aike 6, Formación La Matilde 7, Formación Bajo Grande 8, Formación Baqueró 11, Basalto Cerro del Doce 14, Formación Monte León 17, Basalto la Angelita

21, Depósitos de antiguas playas y cordones litorales 23, Depósitos de Planicies aluviales 25, Depósitos eolicos

26, Depósitos finos de bajos y lagunas 27, Depósitos aluviales y coluviales indiferenciados

Mapa confeccionada a partir de la Hoja Geologógica Tres Cerros (Panza 1994)

Fig. 2. Localizaron de las fuentes sobre las formaciones geológicas

(Panza, 1994). En él se calculó el porcentaje de cobertura areal de cada afloramiento. Esto permitió obtener información sobre el paisaje de la localidad y sobre las potencialidades para la localización de fuentes (Cattáneo, 2002; Hermo, 2008), información que formó parte del diseño de las prospecciones. El cálculo de la superficie de las formaciones geológicas, se considera un estudio inicial, pero por sí solo no es útil para discutir las estrategias tecnológicas de los grupos que habitaron el área de estudio (Hermo, 2008). Así, sobre el mapa confeccionado, se superpusieron los puntos correspondientes a las fuentes identificadas, contrastándose la información geológica y bibliográfica con los datos del campo.

La clasificación de las rocas se realizó considerando que las mismas pueden encontrarse de manera aislada en el paisaje o estar agrupadas en fuentes primarias o secundarias (sensu Nami 1992). A su vez, en el Macizo del Deseado los afloramientos suelen agrupar más de un tipo litológico (Cattáneo,
2002; Frank et al. 2013; Frank et al. 2007; Hermo, 2008; Skarbun \& Páez, 2012). De esta manera, se definieron macroscópicamente los tipos de rocas presentes en el paisaje de la localidad, se estudió su calidad y distribución; asimismo se analizaron las características principales de las fuentes (incluidas las potenciales) (Bellelli, 2005) en cuanto al tipo de materia prima que presentan, y a las características espaciales -tipo, localización, relación con otros sitios y accesibilidad-.

Las rocas se clasificaron en altamente distribuidas, cuando se identificaron (a nivel macroscópico) agrupadas en tres o más sectores de la localidad; en medianamente distribuidas, cuando se localizan agrupadas en dos sectores; y escasamente distribuidas, cuando se ubican en un solo sector (Skarbun, 2011).

La calidad se evaluó en relación a su potencial para producir instrumentos mediante la talla y a su desempeño durante el uso. Las materias primas se clasificaron en excelentes, muy 
buenas, buenas, regulares y malas. Para ello se consideraron variables macroscópicas tales como el tamaño y la homogeneidad del grano, la presencia de inclusiones y el tipo de fractura (Bamforth, 1992; Franco, \& Aragón, 2004; Nami, 1992). A su vez, miembros del equipo de investigación realizaron trabajos experimentales en talla lítica con materiales de la zona de estudio. Estos sirvieron para relacionar la calidad para la talla y el uso con las diferentes características macroscópicas de las distintas rocas (Cueto, 2009; Frank, 2011).

Por otra parte, las fuentes se diferenciaron en dos tipos: primarias -poseen material en forma de manto o filones $\mathrm{u}$ otras manifestaciones geológicas originarias de la zona- y secundarias -agrupan materiales transportado por agentes naturales- (Nami, 1992).

También, se clasificaron según su distancia a otros sectores del paisaje. Se siguieron los criterios propuestos por Civalero \& Franco (2003), considerando como inmediatamente disponibles, aquellas fuentes que se encuentran a menos de 1 $\mathrm{km}$ de alguno de los sitios conocidos; como locales cercanas, cuando se encuentran dentro de los 10 $\mathrm{Km}$; en locales lejanas, cuando se encuentran dentro de los $40 \mathrm{Km}$; y en no locales, las procedentes de más de $40 \mathrm{~km}$.

La evaluación de la accesibilidad se realizó considerando que la misma se relaciona con la facilidad o dificultad de alcanzar una localización, considerando la topografía, la hidrografía, la fitografía y las variaciones estacionales. Para su discusión en la localidad no se incluyo la variable fitogeográfica ${ }^{1}$. La primera se calculó midiendo el porcentaje de superficie con pendientes mayores a $40^{\circ}$ en el entorno inmediato de las fuentes $(0,5 \mathrm{~km})$ y en el entorno de $5 \mathrm{~km}$. El primero representa una superficie de $0,78 \mathrm{~km}^{2}$, mientras que en entorno de $5 \mathrm{~km}$, representa una superficie de $78 \mathrm{~km}^{2}$. Se considera que las pendientes mayores a $40^{\circ}$ son las que proporcionan mayores riesgos para la circulación y el traslado (Matteucci \& Scheinsohn, 2004). De esta manera, fueron consideradas fuentes accesibles aquellas que poseían menos del $50 \%$ de la superficie del entorno inmediato y de $5 \mathrm{~km}$ con pendientes mayores a $40^{\circ}$. La pendiente del terreno se calculó utilizando un modelo de

1 Dadas las características fitográficas del área de estudio no se considera que la vegetación haya sido un factor elevación digital (DEM) ASTER GDEM producido por METI y NASA. La accesibilidad en relación a la hidrología se analizó considerando cambios de 5 $m$ en el nivel de las lagunas y zanjones. Para ello se generó, a partir del DEM, curvas de nivel de $5 \mathrm{~m}$ de equidistancia. Así, se localizaron las fuentes que se emplazan entre las cotas actuales de los márgenes de lagunas y la cota de $5 \mathrm{~m}$ inmediatamente superior.

\section{RESULTADOS DE LAS INVESTIGACIONES SOBRE MATERIAS PRIMAS DE LA LOCALIDAD ARQUEOLÓGICA LA MARÍA}

\section{Características litoestratigráficas}

Las características litoestratigráficas de la localidad arqueológica La María son similares que las del resto del Macizo del Deseado. El estudio de la Hoja Geológica Tres Cerros (Panza, 1994) indica que las formaciones potencialmente ricas en rocas silíceas, de buena a excelente calidad para la talla, ocupan la mayor parte del área de estudio (Fig. 2). Puede reconocerse el grupo Bahía Laura representado predominantemente por la Formación Chön Aike, que cubre un $50 \%$ del área, y con escasa representación la Formación La Matilde, que solo cubre un 1,5\%. La Formación Bajo Pobre abarca un 5,80 \%. Por otra parte, la Formación Baqueró cubre casi un 15 \% del área; si bien la bibliografía arqueológica y geológica del macizo no identifica esta formación con afloramientos de rocas aptas para la talla, durante los trabajos investigación se reconoció una de las fuentes de aprovisionamiento aflorando sobre la misma (Fig. 2). Asimismo, se distinguen depósitos del Pleistoceno superior - Holoceno, donde pueden identificarse fuentes secundarias de materias primas silíceas, entre ellos se encuentran los depósitos de antiguas playas y cordones litorales lacustres, depósitos de planicies y conos aluviales del Pleistoceno superior - Holoceno, depósitos de bajos y lagunas; y depósitos aluviales y coluviales indiferenciados. También se presentan los basaltos -Alma Gaucha y La Angelitadonde potencialmente pueden hallarse rocas de importancia para los grupos humanos pasados,

influyente para la accesibilidad a las fuentes. 
por ejemplo aquellas utilizadas como percutores.

\section{Las fuentes de materias primas}

Se localizaron y estudiaron 16 afloramientos en toda la localidad. Dado que la misma abarca un área de $226 \mathrm{~km}^{2}$, implicaría 1 cada $14,13 \mathrm{~km}^{2}$. Sin embargo, debe tenerse en cuenta que también se identificaron concentraciones primarias pequeñas o materiales aislados de rocas de sílex, tobas silicificadas y crestones silicificados; y que pueden encontrarse fuentes secundarias de recursos líticos de diferente origen en los zanjones y cuencas endorreicas. Si bien, en la mayoría de los casos no fueron cuantificadas o georeferenciadas, debe rescatarse de manera cualitativa su presencia en el área.

De los 16 afloramientos (Tabla 2 y Fig. 1), 6 fueron localizados durante los trabajos de prospección en una escala amplia. LMSO fue identificado durante la realización de una transecta de $8 \mathrm{~km}$ en el sector suroeste de la localidad. La misma se planteo a $3 \mathrm{~km}$ al oeste del sitio CDM1 sobre el mismo paralelo que el sitio (48 33' 40") y siguiendo el meridiano $68^{\circ} 53^{\prime \prime} 35^{\prime}$ hacia el norte, en un sector con poca información arqueológica. Fue localizado a los 3,38 km del punto de partida y aflora sobre la formación Baqueró (Fig. 2). Es un afloramiento pequeño, accesible y local cercano con respecto al sitio CDM1 (Tabla 2). Fue descripto como un conglomerado de bloques y nódulos de sílex.

La fuente $C C B$ fue identificada en el sector centro este de la localidad en una prospección que unía la localidad arqueológica La María con el sitio arqueológico El Ceibo (EC). Se realizó una transecta de 7,5 km que se inició en el camino que lleva al casco de la Estancia La María hacia el este, y finalizó en EC. Fue identificada a 4,6 km del comienzo de la transecta, al noroeste del bajo que conecta la localidad La María con EC y aflora sobre la formación Chön Aike (Fig. 2). Es una fuente grande, accesible y, local cercana con respecto al sitio EC (Tabla 2). Las rocas predominantes son bloques y nódulos de sílex rosado de buena a muy buena calidad para la talla. Posee evidencias de explotación.

CC 1 y 2 fueron localizadas en el sector noroeste de la localidad durante una transecta realizada desde el camino que une la ruta de entrada al casco de La María con el BP, hacia el norte. CC 1 se encuentra más al sur sobre el principio de la transecta. Aflora sobre la formación Chön Aike (Fig. 2). Es pequeña, accesible, y, local cercana con respecto al sitio CV (Tabla 2). Las rocas se presentan como nódulos de sílex rojo. CC 2 , se localiza 1,2 km hacia el norte de la fuente previa. También aflora sobre la formación Chön Aike (Fig. 2), es pequeña, accesible y local cercana LMB (Tabla 2). Las rocas se presentan como nódulos de sílex amarillo

La fuente LMN 1, se encuentra en el sector noroeste de la localidad, a 0,2 km del casco de la estancia, a 0,3 $\mathrm{km}$ de la desembocadura del cañadón de los sauces y a 0,2 km de la naciente del cañadón de la Lavandería. Estos cañadones forman parte de un paisaje que conecta el bajo de la Laguna Grande de La María con el manto basáltico que corona el sector, sirviendo de camino alternativo a los paredones abruptos que conforman el basalto. Aflora sobre la formación Chön Aike (Fig. 2), es pequeña, accesible y esta inmediatamente disponible al sitio CLV (Tabla 2). La materia prima se presenta en forma de nódulos de sílex marrón. La fuente LMN 2 se encuentra a $0,4 \mathrm{~km}$ del Basalto, sobre un pequeño cañadón que permite el acceso al mismo, también en el sector noroeste de la localidad. Esta a 0,75 km de la fuente $L M N 1$ y a $1 \mathrm{~km}$ de $L M Q$. Aflora sobre la formación Chön Aike (Fig. 2), es pequeño, accesible y local cercano con respecto al sitio LMQ (Tabla 2). Presenta toba silicificada con evidencias de explotación.

Otros 8 afloramientos fueron estudiados de manera contextual. $C V$ fue localizado a partir de las investigaciones realizadas en la zona del cañadón de La Ventana, en el sector noreste de la localidad. Se ubica al sur del cañadón del mismo nombre, que desemboca en el sector sur de la Laguna grande de La María. Aflora sobre la formación Chön Aike (Fig. 2), es una fuente mediana, accesible e inmediatamente disponible a CV (Tabla 2). Los materiales se presentan en forma de bloques y nódulos de sílex y toba silicificada de buena y muy buena calidad, la cantera presenta evidencias de explotación.

LMQ se ubica en el cañadón de la María Quebrada, en el sector noroeste de la localidad. 

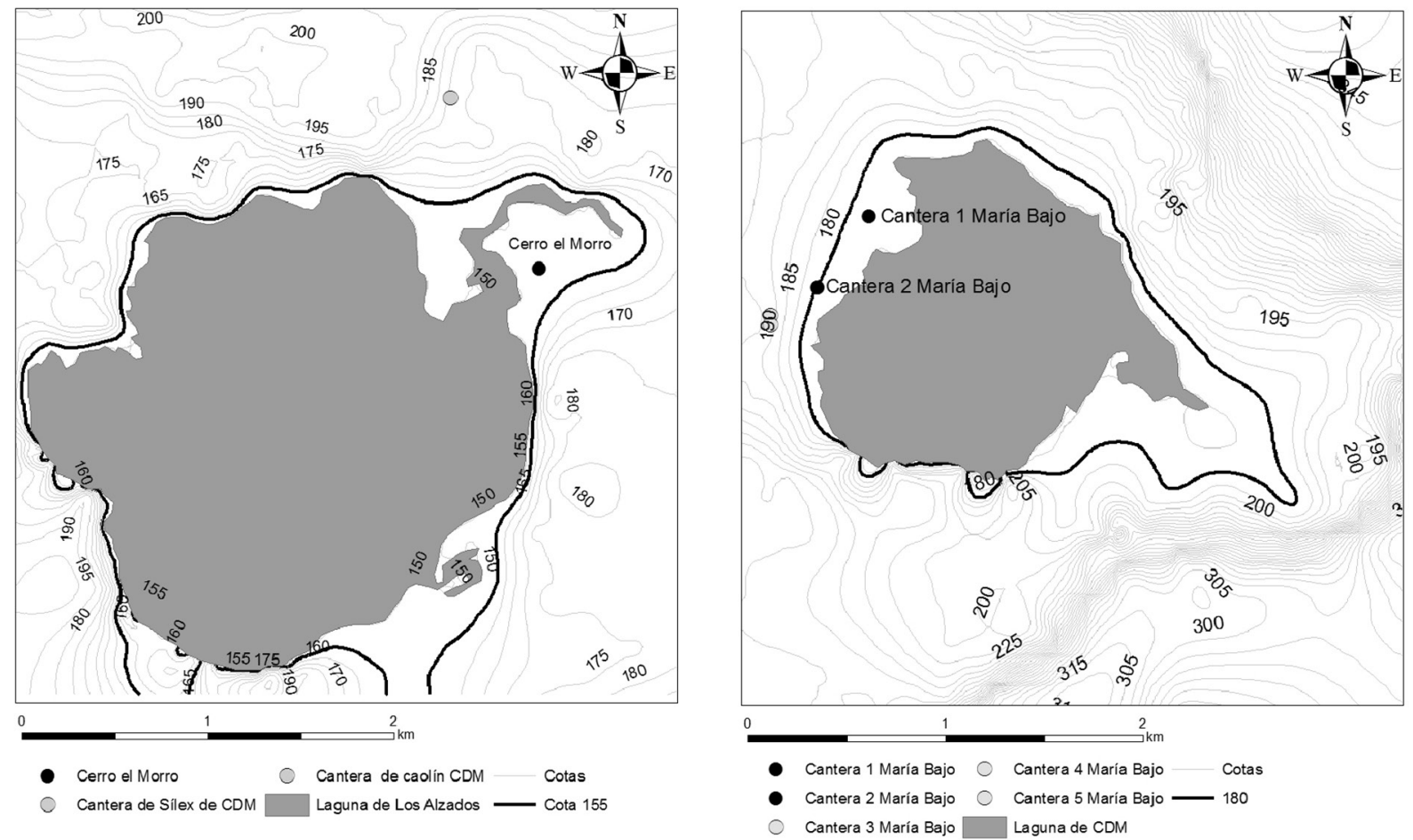

Fig. 3. Accesibilidad de las fuentes según cambios en los niveles de las lagunas.

Aflora sobre la formación Chön Aike (Fig. 2), es un afloramiento pequeño, accesible e inmediatamente disponible al sitio LMQ (Tabla 2). Se registró sílex pardo-ocre de buena calidad para la talla (Paunero et al. 2005). La materia prima se presenta en forma de filón sobre la pared de una de las cuevas localizada cerca de la zona que da acceso al manto de basalto. Posee evidencias de explotación.

$C M$ se localiza en el sector suroeste de la localidad. Aflora en forma de morro, elevándose $20 \mathrm{~m}$ por encima de depósitos de antiguas playas y cordones lacustres litorales, los cuales son contiguos a la Formación La Matilde (Fig. 2). Se localiza en el bajo de la Laguna de Los Alzados a aproximadamente $0,5 \mathrm{~km}$ al este de ella, entre el nivel de cota actual de la laguna y la cota $5 \mathrm{~m}$ inmediatamente superior (Fig. 3). De esta manera, se considera que pudo haber quedado aislada $e$ inaccesible en los periodos de mayor régimen hídrico (Paunero, 2009). Es una fuente grande, accesible y local cercana con respecto al sitio CDM1 (Tabla 2). La materia prima se presenta concentrada como parte del mismo morro y se compone por material tobáceo silicificado, de color pardo-violáceo (Paunero et al. 2005), la calidad para la talla es de regular a buena, se identificaron evidencias de explotación de la misma.

Las fuentes $L M B 1,2,3,4$ se localizan en el sector noreste de la localidad y LMB 5 en el noroeste. Se encuentran al noreste de la laguna Grande de La María, la máxima distancia entre ellas es de 1,5 km y todas están inmediatamente disponibles a los sitios del cañadón de La María Baja, son pequeñas (la fuente LMB 3 es muy pequeña) y accesibles (Tabla 2 ). Todas, a excepción de LMB 5, se localizan sobre pequeñas elevaciones del terreno. LMB 3, 4 y 5 afloran sobre la formación Chön Aike, mientras que LMB 1 y 2 lo hacen sobre depósitos aluviales y coluviales indiferenciados (Fig. 2). A su vez, LMB 1 se localiza entre el nivel de la cota actual de la laguna y la cota de $5 \mathrm{~m}$ inmediatamente superior; mientras que la LMB 2 se ubica en el límite con esta última cota (Fig. 3). Estas características locacionales, llevan a considerar que ambas fuentes pudieron haber quedado inundadas o inaccesibles en los periodos de mayor régimen hídrico. En todas las fuentes LMB las materias primas se presentan en forma de bloques y nódulos 
Tabla 2. características de las fuentes de aprovisionamiento.

\begin{tabular}{|l|l|l|l|l|l|}
\hline Fuente & $\begin{array}{l}\text { Tamaño } \\
\text { estimado } \\
\mathrm{km}^{2}\end{array}$ & $\begin{array}{l}\text { Porcentaje } \\
\text { pendiente } \mathrm{en} \\
0,5 \mathrm{~km}\end{array}$ & $\begin{array}{l}\text { Porcentaje } \\
\text { pendiente en } \\
5 \mathrm{~km}\end{array}$ & $\begin{array}{l}\text { Sitio más } \\
\text { cercano }\end{array}$ & $\begin{array}{l}\text { Sitio } \\
\text { más } \\
\text { cercano } \\
\text { en km2 }\end{array}$ \\
\hline La María SO (LMSO) & pequeño & 2,05 & 0,08 & CDM1 & 4,019 \\
\hline Camino a El Ceibo (CCB) & grande & 0,00 & 0,19 & CB & 2,941 \\
\hline Cuevas del camino 1 (CC1) & 0,031 & 0,00 & 0,09 & CV & 2,079 \\
\hline Cuevas del camino 2 (CC2) & 0,001 & 0,00 & 0,00 & LMB & 1,988 \\
\hline La María Norte 1 (LMN1) & 0,015 & 0,00 & 0,00 & CLV & 0,681 \\
\hline La María Norte 2 (LMN2) & pequeño & 1,02 & 0,00 & LMQ & 1,321 \\
\hline Cantera de La Ventana (CV) & 0,086 & 0,00 & 0,00 & CV & 0,629 \\
\hline Cerro el Morro (CM) & 0,116 & 0,00 & 0,00 & CDM1 & 1,644 \\
\hline La María Bajo 1 (LMB1) & 0,024 & 0,00 & 0,00 & LMB & 0,801 \\
\hline La María Bajo 2 (LMB2) & 0,009 & 0,00 & 0,00 & LMB & 0,507 \\
\hline La María Bajo 3 (LMB3) & 0,0003 & 0,00 & 0,00 & LMB & 0,352 \\
\hline La María Bajo 4 (LMB4) & 0,001 & 0,00 & 0,00 & LMB & 0,384 \\
\hline La María Bajo 5 (LMB5) & 0,014 & 0,00 & 0,11 & LMB & 0,652 \\
\hline La María Quebrada (LMQ) & pequeño & 0,00 & 0,83 & LMQ & 0,587 \\
\hline Bosque petrificado (BP) & 2,445 & 0,00 & 0,29 & CLV & 3,730 \\
\hline Cantera de Sílex de CDM (CSCDM) & 0,15 & 0,00 & 0,47 & CDM1 & 0,616 \\
\hline
\end{tabular}

LMSO: La María SO; CCB: Camino a El Ceibo; CC1: Cuevas del camino 1; CC2: Cuevas del camino 2; LMN1: La María Norte 1; LMN2: La María Norte 2; CV: Cantera de La Ventana; CM: Cerro el Morro; LMB1: La María Bajo 1; LMB2: La María Bajo 2; LMB3: La María Bajo 3; LMB4: La María Bajo 4; LMB5: La María Bajo 5; LMQ: La María Quebrada; BP: Bosque petrificado; CSCDM: Cantera de Sílex de CDM.

de sílex y toba silicificada de buena y muy buena calidad. Los colores son variados, aunque se identificó en LMB 3 mayor presencia de colores amarillos y en LMB 5 de marrón. Todas presentan evidencias de explotación.

Por último, se estudiaron sistemáticamente dos fuentes: la CSCDM (Frank et al. 2007) y BP (Frank et al. 2013). CSCDM se encuentra en el sector suroeste de la localidad, a $0,4 \mathrm{~km}$ al norte de la laguna de Los Alzados, sobre el bajo que rodea la laguna, inmediatamente disponible al sitio CDM1. Aflora sobre la formación Baqueró (Fig. 2), es una fuente grande y accesible (Tabla 2). A partir del año 2000 se realizó el relevamiento fotográfico, geoposicionamiento de algunos rasgos, las primeras mediciones y se definieron algunas de las características del tipo de roca presente (Paunero, 2000). Los límites se definieron mediante dos transectas, la primera une al sitio con la laguna de Los Alzados, la segunda cruza a la primera transversalmente. A partir de ellas se midió el largo -1 km-y ancho -0,4 km- máximo de la dispersión del material. La zona de mayor concentración se delimito en el sector central. Fue caracterizada por el geólogo Dr. Ramiro Lopez como una fuente primaria, compuesta por abundante material suelto producto del precipitado de un fluido (frío) sobresaturado en sílice (López, 2004). La materia prima se presenta en forma de bloques y nódulos. Fue definida como cantera taller, debido a la presencia de productos de la talla de estadios avanzados de la reducción de los núcleos y a la presencia de algunos artefactos formatizados (Paunero et al. 2005). A partir del año 2005 se comenzó con el estudio sistemático de la fuente y la clasificación in situ del material. Para esta clasificación se delimitó un sector de 0,0016 km² en la zona de mayor densidad, sobre la transecta de mayor longitud. En este sector se planteó una grilla subdividida en 400 cuadriculas de $4 \mathrm{~m}^{2}$, de las cuales fueron seleccionadas 113 siguiendo un muestreo sistemático. Además se formularon 21 cuadrículas 
del mismo tamaño realizadas cada $0,5 \mathrm{~km}$ a lo largo de la transecta (Frank et al. 2007). En el sector de mayor densidad se registraron 2048 elementos, de los cuales 607 fueron nódulos y núcleos, lo que implican una densidad de 1,34 nódulos-núcleos/ $\mathrm{m}^{2}$. Mientras que fuera de este sector se registraron 40 nódulos y núcleos $\left(0,47\right.$ nódulos-núcleos $\left./ \mathrm{m}^{2}\right)$. Los nódulos y núcleos más abundantes presentan un diámetro menor a $20 \mathrm{~cm}$. El 87,51\% es menor a $10 \mathrm{~cm}$, el $9,72 \%$ está entre 10 y $20 \mathrm{~cm}$ y el $3,13 \%$ es mayor a $20 \mathrm{~cm}$. Las características macroscópicas de las rocas varían según el grado de silicificación, de homogeneidad y la presencia de inclusiones. El grosor y la homogeneidad de la corteza afectan la calidad y la productividad de los nódulos, los sílex rojos generalmente presentan una corteza delgada y homogénea que no necesita ser descortezada durante su reducción. De esta manera, la calidad para la talla de las rocas es heterogénea, sin embargo en su mayoría son de buena o muy buena calidad. La coloración de las rocas también es variable, aunque predomina el rojo y el amarillo, se registraron otros colores como violeta, verde y gris. El 76,44\% de de los núcleos están activos, de ellos el 25,15\% son de reducción inicial; cerca del $98 \%$ son poliédricos. También se ha reconocido una muy baja cantidad de núcleos bifaciales, globulosos, prismáticos y piramidales (Frank et al. 2007). Por otra parte, los productos de la talla son el grupo artefactual más abundante, se identificaron 1379 piezas que representan el $67,33 \%$ del total. La mayoría son lascas producidas durante la talla $(58,63 \%)$, un $37 \%$ corresponde al descortezamiento y un $2 \%$ a la formatización final. Además, casi el $15 \%$ de las piezas producidas durante talla presenta corteza. Se registró un alto porcentaje de talones lisos (42\%) y naturales (36\%) característicos de las primeras etapas de reducción (Frank et al. 2007).

Por otra parte, $B P$ se encuentra en el sector noroeste de la localidad, a 2,5 km de laguna Grande de La María, a 2,8 km del cañadón de La María Bajo, a 3,9 km de Cueva Túnel y 2,3 $\mathrm{km}$ a CLV, de esta manera es considerada una fuente local cercana. Es una fuente muy grande y accesible (Tabla 2). Se emplaza en el sector central de una cuenca endorreica, sobre un conjunto de elevaciones, alrededor de los 230 msnm (Fig. 2). La visibilidad del emplazamiento es baja dado que la distancia máxima desde donde se visualiza la fuente es de 0,1 km (Frank et al. 2013). Sin embargo, una vez en el lugar, la visibilidad es alta, debido al tamaño de algunos de los materiales. Se trata de una fuente primaria (sensu Nami, 1992), la materia prima predominante es la madera petrificada (Frank et al. 2013). La bibliografía geológica para la región indica que los troncos silicíficados son de origen Jurásico, probablemente correspondiente a Araucaria mirabilis; también, suele asociar a la Formación La Matilde como la portadora de estos grandes troncos (Gnaedinger \& Herbst, 2006; Panza, 1994), no obstante, en la localidad La María, como indica la Fig. 2, la mayoría de estos troncos se localizan sobre las formaciones Chön Aike y Bajo Pobre. Desde el año 2003 se realizaron estudios contextuales en esta fuente, donde se definieron los límites de la dispersión en el sector históricamente conocido de la cantera, los tipos de roca presentes y se registraron evidencias de explotación humana de la misma. A su vez, se realizaron otras dos transectas diseñadas para definir los límites espaciales. La primera de E-O de $3,5 \mathrm{~km}$ de largo, se inicio a $0,2 \mathrm{~km}$ al norte y 1,5 $\mathrm{km}$ al este del sector conocido y se finalizó a 2 $\mathrm{km}$ al oeste del mismo. Esta transecta mostró que la cantera se extendía hacia el norte y que había una dispersión constante de materiales a lo largo de la misma aunque con una frecuencia variable, concentrándose el sector de mayor frecuencia en el centro de la transecta. La otra transecta E-O de $1,750 \mathrm{~km}$ cruzaba el primer sector conocido de la cantera. El área total prospectada en esta última fue de $0,106 \mathrm{~km}^{2}$. A nivel macroscópico se identificó un predominio de xilópalo con una frecuencia de 1467 piezas, junto con variedades de sílex (211 piezas), y tobas silicificadas (123 piezas). También se identificaron rocas de toba y calcedonia en muy baja cantidad. Se registró la presencia de 218 bloques, 1210 nódulos, 174 núcleos, 100 fragmentos indiferenciados, 569 productos de la talla y 2 instrumentos, con una densidad de 0,013 bloques, nódulos y núcleos/ $\mathrm{m}^{2}$ y 0,005 productos de talla $/ \mathrm{m}^{2}$. El análisis de las dos transectas mostró que los elementos se presentan a modo de "parches" en los cuales se observan grandes bloques -los troncos silicificadosy en torno a ellos se concentra la mayor parte de los restos artefactuales. También puede observarse 
concentraciones en puntos alejados de estos bloques, en zonas más bajas y reparadas (Frank et al. 2013). A partir del año 2008 se comenzó con el estudio sistemático de la fuente. El diseño del grillado para la clasificación tecnomorfológica se llevo a cabo considerando esta forma de presentación de los materiales. Se establecieron 4 grillas de $10 \mathrm{~m}$ x $10 \mathrm{~m}$ cada una en el sector de mayor concentración de bloques de la transecta, localizadas alrededor de un tronco central. Estas fueron subdivididas en 25 cuadrículas de $4 \mathrm{~m}^{2}$. De cada grilla se seleccionaron diez cuadrículas sobre las que se realizó la clasificación in situ de todo el material (Frank et al. 2013). De esta manera, el área analizada fue de $160 \mathrm{~m}^{2}$. Se registraron 949 nódulos, 78 bloques y 6730 artefactos, de los cuales 387 fueron clasificados como núcleos, lo que da una densidad de 8,84 núcleos-nódulos-bloques/ $\mathrm{m}^{2}$. Los núcleos se encuentran en su mayoría aún activos, y el $73 \%$ presenta corteza. Su tamaño fluctúa habitualmente entre 4 y $12 \mathrm{~cm}$ de longitud máxima. En particular, dominan los poliédricos. También se registraron 5.744 productos de talla $(79,97$ \%) y 25 artefactos formatizados. Macroscópicamente el 98,9\% de los materiales se clasificó como xilópalo, siendo la calidad de la materia prima entre regular $(43,4 \%)$ y buena (40,9\%) (Frank et al. 2013). Entre los productos de talla predominan los correspondientes a la talla del núcleo, gran parte de estas piezas (39\%) presentan corteza, indicando su vinculación con las primeras etapas del proceso de producción. A su vez, se registró escasa representación de las etapas finales. Los artefactos formatizados corresponden casi en su totalidad a lascas retocadas (Frank et al. 2013).

\section{DISCUSIÓN Y CONSIDERACIONES FINALES}

Las evidencias provenientes del estudio de la estructura de los recursos líticos en la Localidad arqueológica La María y sus zonas vecinas, evidencian que existe una alta disponibilidad $y$ distribución de materias primas. En su mayoría, estas presentan calidad de regular a muy buena, encontrándose también rocas de mala calidad como excelente. Principalmente se reconoce una variedad de materiales silíceos, con diferente grado de silicificación.

La mayor parte de las fuentes se halla al norte de la localidad. Se identificaron hasta el momento 12 , de las cuales 10 afloran sobre la formación Chön Aike. Solo LMB 1 y 2 lo hacen sobre depósitos aluviales y coluviales indiferenciados. Las fuentes más frecuentes son las que presentan sílex y toba silicificada $(n=6)$, seguidas por las de sólo sílex $(n=4)$ y una presenta únicamente toba silicificada. Así, puede considerarse que las rocas de sílex y toba silicificada se encuentran ampliamente distribuidas en el sector norte de la localidad. Todas las fuentes se encuentran a menos de 5 $\mathrm{km}$ de alguno de los sitios conocidos, así fueron caracterizadas como locales cercanas. Sumado a esto, 8 de ellas -las 5 fuentes LMB, LMQ, CV y LMN1-, se encuentran inmediatamente disponibles para al menos alguno de los sitios. Sin embargo, debido a las características locacionales de LMB 1 y 2 -afloran sobre depósitos aluviales y coluviales indiferenciados y LMB 1 se localiza entre el nivel de la cota actual de la laguna y la cota $5 \mathrm{~m}$ inmediatamente superior-, es probable que durante el Pleistoceno final, con un mayor régimen hídrico, no hayan estado disponibles. Aun así, esto no debió afectar la disponibilidad y variabilidad de fuentes, ya que las mismas se encuentran en un sector con alta disponibilidad de rocas.

La mayoría de estas fuentes, fueron conocidas y utilizadas como canteras o canteras taller por lo grupos que habitaron la región, ya que existen evidencias de que fueron explotadas. En este sentido, LMQ se encuentra inmediatamente disponible a los sitios La Mesada y Cueva Túnel. Estos sitios presentan materias primas que, de acuerdo a sus características macroscópicas, podrían provenir de LMQ. Las investigaciones realizadas en el componente inferior de Cueva Túnel (Frank, 2011; Skarbun, 2011; Skarbun et al. 2013) indican que un $24 \%$ aproximadamente de la materia prima corresponde al sílex marrón. Para el sitio La Mesada, en el componente inferior (Holoceno temprano) el sílex marrón se presenta en un $46 \%$ mientras que para el componente correspondiente al Holoceno medio en un $24 \%$ (Skarbun, 2009, 2011). Esto implicaría un uso medianamente frecuente de esta roca, por lo menos, para los sitios que se encuentran inmediatamente disponibles. No obstante, un porcentaje alto de los materiales de dichos sitios no provendrían de esta cantera. Así, se habrían explotado frecuentemente 
otras fuentes.

Por otra parte, existen cuatros fuentes potenciales de sílex donde no fueron registradas evidencias de explotación. Las mismas se localizaron a partir de muestreos de amplia escala. La falta de evidencia podría estar más relacionada a los objetivos particulares con los cuales fueron realizados los muestreos que al uso o no de las fuentes, ya que estos buscaban relevar información arqueológica en escala amplia y con baja resolución.

Por último, en sector norte, también se encuentra BP, fuente que se caracteriza por su concentración de xilópalos. Esta roca se encuentra escasamente distribuida, dado que sólo se localiza de manera abundante en esta fuente -aunque el xilópalo puede hallarse discontinuamente y en baja cantidad en toda la localidad-. Las características tecnológicas de los conjuntos mostraron que fue utilizada como cantera taller, donde se realizó el aprovisionamiento de nódulos y las primeras etapas de la preparación y el descortezamiento de los núcleos.

En el sector central de la localidad se identificó, hasta el momento, una cantera local grande (CCB), que aflora sobre Chön Aike, presenta rocas de silex rosa y evidencias que indicarían que fue conocida y utilizada por los grupos del pasado.

En el sector suroeste de la localidad se identificaron, por el momento, tres fuentes. Dos de ellas se sitúan cercanas al sitio CDM1. Las rocas presentes son el sílex y la toba silicificadas. De acuerdo a la información de la Hoja Geológica CSCDM aflora sobre la formación Baqueró, mientras que $\mathrm{CM}$ lo hace sobre depósitos de antiguas playas y cordones lacustres litorales. Sin embargo, es probable que pertenezcan a la formación La Matilde. En primer lugar, a menos de $1 \mathrm{~km}$ de ambas se encuentra un pequeño afloramiento de esta formación; luego, durante el análisis litológico de segmentos delgados se identificaron dos muestras provenientes de la CSCDM como rocas piroclásticas retrabajadas posiblemente de la formación La Matilde (Skarbun \& Páez, 2012); por último, los depósitos de antiguas playas y cordones lacustres litorales donde se localiza $\mathrm{CM}$ son contiguos a la formación La Matilde y esta fuente se eleva $20 \mathrm{~m}$ por encima de los mismos. Futuros análisis geológicos podrán esclarecer mejor estas cuestiones. Estas fuentes fueron conocidas y utilizadas por los grupos que habitaron el área. Las características tecnológicas de los conjuntos estudiados en CSCDM indican que fue utilizada como cantera taller, donde principalmente se realizó el aprovisionamiento de nódulos y las primeras etapas de su reducción. La cercanía al sitio CDM1 permite hipotetizar que los núcleos descortezados, lascas nodulares o las formas bases fueron trasladados al sitio, la presencia mayoritaria de sílex, particularmente rojo en el sitio, permite sostener esta idea (Frank, 2011; Skarbun, 2009, 2011). Del mismo modo, CM debió ser explotada por los grupos que ocuparon las inmediaciones del sitio CDM1, si bien pudo no haber estado accesible durante el Pleistoceno final, dado que el aumento del nivel de la laguna adyacente pudo haberla dejado como una isla (Paunero, 2009). En este sentido, las características de color y textura de algunas de las tobas silicificadas del sitio CDM1 para los componentes más tardíos muestran similitudes con los materiales identificados en $\mathrm{CM}$. No obstante, no se ha podido establecer aún esto para los componentes del Pleistoceno final.

Así, si bien se identificó por el momento mayor distribución y disponibilidad más amplia de recursos en el norte de la localidad, esto no afectaría la disponibilidad de rocas silíceas de buena calidad disponibles en las inmediaciones de ninguno de los sitios estudiados. Sin embargo, sí podría afectar la variabilidad de fuentes posibles de ser utilizadas o la intensidad de explotación de las mismas, ya que los sitios del sector norte poseen mayor cantidad de fuentes disponibles dentro de los $5 \mathrm{~km}$. De todas maneras, esta diferencia en la disponibilidad podría relacionarse al muestreo, ya que existen más zonas sin información arqueológica en el sector sur de la localidad, y las evidencias indican que durante todas las prospecciones realizadas siempre fueron identificadas zonas con rocas silíceas aptas para la talla. Esto permite suponer que a medida que se continúe con las prospecciones en el sector, se irá incrementando el número de fuentes conocidas.

En cuanto a la accesibilidad de las fuentes, en general los paisajes donde se localizan no poseen pendientes que dificulten su acceso. Solo zonas muy pequeñas -como para considerar que pueden afectar el acceso del entorno de algunas canteras- poseen pendientes mayores a $40^{\circ}$. De todas formas, cuando se discute la accesibilidad, hay 
que tener en cuenta las modificaciones estacionales del paisaje (Cattáneo, 2002). En este sentido las fuentes LMB1, 2 y $\mathrm{CM}$ pudieron tener acceso restringido durante los meses invernales, dada su ubicación en cercana a los bordes de laguna.

En cuanto a las estrategias de selección, obtención y economía de las materias primas las evidencias provenientes de los sitios arqueológicos estudiados muestran que generalmente los artefactos de sílex son los que tienen la frecuencia más alta en todos los componentes. Esta roca, de muy buena calidad para la talla, es la que se encuentra más ampliamente distribuida en la localidad, se presenta en 13 fuentes. A su vez, la mayoría de los sitios estudiados cuentan con por lo menos una fuente con presencia de sílex a menos de $1 \mathrm{~km}$. Esta forma de distribución permite comprender porque se desplegaron sobre las rocas de sílex estrategias que no buscaban su economía, ya que estos comportamientos son comunes en los paisajes donde las materias primas están ampliamente disponible y son de buena calidad para la talla (Andrefsky, 1994). Si bien, la cantidad de fuentes con presencia de toba silicificada también es alta (se presenta en nueve fuentes), su calidad suele ser menor al sílex, esto podría ser una de las variables que explica su baja frecuencia en los sitios.

En contraposición, en varios de los componentes de la localidad se registró la presencia de xilópalo, aunque en porcentajes muy bajos. Sobre esta materia prima se desplegaron estrategias de mayor economía e inversión de energía en la producción de artefactos formatizados. Dado que se habrían ingresado a los sitios las preformas o los artefactos ya finalizados, como parte del equipo personal, con diseños conservados, transportables y versátiles (Skarbun, 2011). La presencia de una sola fuente de xilópalo en la localidad, aunque con abundante material en ella, podría explicar su mayor grado de economía y su amplia circulación dentro de la localidad, alcanzando sitios que se encuentran a más de los $5 \mathrm{~km}$ de distancia. Sin embargo, la evidencia de una explotación reiterada de esta cantera, indica que deberían existir zonas donde se debió transportar más frecuentemente el xilópalo. Es posible que esto suceda en las zonas más próximas, disminuyendo la frecuencia de explotación a medida que se aleja de la misma. No obstante, hasta el momento, no se identificaron sitios estratigráficos cercanos a $\mathrm{BP}$ que permitan discutir el modo en que se explotó esta roca en las cercanías de la fuente (Frank et al. 2013).

Asimismo, en relacion a la estandarización de formas base laminares durante el Holoceno medio, la. abundancia, amplia distribución y disponibilidad de rocas locales de excelente a buena calidad indican que la cantidad de materias primas no sería un factor de riesgo (sensu Bousman, 2005) en este paisaje. Esto apoyaría la idea de que la tecnología laminar estaría relacionada, en este contexto, a la búsqueda de formas base particulares, que al igual que fuera planteado para otros sitios de la región, serían formas predeterminadas, tecnológicamente buscadas (Paunero et al. 2007) con diseños confiables que permitirían el enmangue y recambio luego de la fractura (Hermo, 2008; Hermo \& Magnin, 2012).

Por último, los estudios sobre las estrategias tecnológicas realizados tanto en las canteras como en los sitios estratificados, mostraron que a nivel regional existe una diferenciación espacial en las actividades de manufactura, evidenciada por la preparación de los núcleos y obtención de formas base en las canteras talleres, como es el caso de CSCDM y BP, y la realización del resto de las actividades de producción artefactual en los sitios. Por lo tanto, la predominancia de núcleos poliédricos no agotados en estas fuentes indicaría que se explotaron expeditivamente, sin desarrollar estrategias que optimicen el rendimiento de las materias primas (Frank et al. 2013; Frank et al. 2007; Paunero et al. 2005; Skarbun, 2011). En contraste, la presencia de un número relativamente mayor de núcleos en el componente del Holoceno medio de LM, que en el resto de los componentes de la localidad, indica que los mismos fueron transportados hacia el sitio y descartados allí. Esta estrategia de aprovisionamiento y descarte muestra diferencias con las implementadas para otros momentos de ocupación del área. Los núcleos pudieron ser llevados al lugar como equipamiento (Franco et al. 2011) para eventuales usos futuros. La mayor diversidad de fuentes se encuentra a menos de $5 \mathrm{Km}$ del sitio, aunque no inmediatamente disponible, el costo de transporte en previsión a futuros usos sería bajo debido al reiterado uso 
de las rocas. Este equipamiento sería beneficioso para ocupaciones de alta intensidad y prolongada duración $y / o$ reiteradas como sería el caso propuesto para las ocupaciones del Holocenos medio.

En suma, este trabajo complementa los diferentes estudios realizados en la región, tanto a nivel local como a nivel regional en el área del Macizo del Deseado. A nivel local, la integración con los estudios de las canteras individuales (Frank et al. 2013; Frank et al. 2007), de los segmentos delgados de materiales provenientes de distintas fuentes (Skarbun \& Páez, 2012), de la organización de la tecnología lítica (Cueto \& Castro, 2012; Frank, 2011; Skarbun, 2009, 2011; Skarbun et al. 2007) permite ampliar el conocimiento sobre la tecnología lítica y las estrategias implementadas en el manejo de los recursos líticos de las sociedades cazadoras recolectoras que habitaron la región desde el Pleistoceno final. A su vez, también aporta a un mayor conocimiento de la variabilidad en la estructura de recursos líticos del Macizo del Deseado, del cual siempre se sostuvo que era un espacio homogéneo, con amplia disponibilidad de materias primas. Sin embargo, diversas investigaciones actuales están dando cuenta de su variabilidad interna (Franco et al. 2011; Hermo, 2008).

\section{AGRADECIMIENTOS}

Este trabajo fue realizado dentro del plan de trabajo de CONICET y en el marco del proyecto "Investigaciones Arqueológicas en la Meseta Central de Santa Cruz: Pasado Humano y Comunicación. Etapa II." N668. SeCyT. UNLP, dirigido por el Lic. Rafael Paunero, a quien le agradezco su apoyo. También agradezco al Dr Pablo Ambrústolo y a Lic. Manuel Cueto la lectura del manuscrito y al Dr Ariel D. Frank la lectura del mismo y la traducción al inglés del resumen. A la Dra. Alicia Castro sus consejos y apoyo. A la familia Behm por la logística y por permitirnos realizar nuestras investigaciones en la Estancia La María. A la comunidad de San Julián y sus autoridades, por recibirnos afectuosamente $y$ brindarnos la ayuda para realizar nuestras tareas. A mis compañeros de equipo, por las tareas de campo y laboratorio.

\section{BIBLIOGRAFÍA}

Aguerre, A. (2003). La cueva 4 de La Martita y las ocupaciones de 8000 años (Santa Cruz, Argentina). En A. Aguerre (Ed.), Arqueología y paleoambiente en la patagonia santacruceña argentina (pp. 27-62). Buenos Aires: Imprenta Nuevo Offset.

Ambrústolo, P. (2010). Estudio de las estrategias de aprovisionamiento y utilización de los recursos líticos por cazadores recolectores en la Costa Norte de Santa Cruz (Patagonia Argentina). Unpublished Tesis doctoral, Universidad Nacional de La Plata, La Plata.

Andrefsky, W. (1994). The geological occurrence of lithic and stone tool production strategies. Geoarchaelogy: An International Journal, 9(5), 375-391.

Bamforth, D. (1992). Quarries in context: A regional perspective on lithic procurement. Stone tool procurement, production and distribution in California prehistory. Institute of Archaeology Series, 2, 131-156.

Belardi, J. (2003). Paisajes Arqueológicos: un estudio comparativo de diferentes ambientes patagónicos. Unpublished Tesis doctoral, Universidad Nacional de Buenos Aires, Buenos Aires.

Bellelli, C. (2005). Tecnología y materias primas a la sombra de Don Segundo. Una cantera-taller en el valle de Piedra Parada. Intersecciones en Antropología, 6, 75-92.

Berón, M., Migale, L. \& Curtoni, R. (1995). Hacia la definición de una Base Regional de Recursos Líticos en el Area del Curacó. Una Cantera Taller: Puesto Córdoba (La Pampa, Argentina). Relaciones de la Sociedad Argentina de Antropología XX 111-128.

Binford, L. R. (1979). Organization and formation processes: looking at curated technologies. Journal of Anthropological Research, 35(3), 255- 273.

Bousman, C. (2005). Coping with risk: Later stone age technological strategies at Blydefontein Rock Shelter, South Africa. Journal of Anthropological Archaeology, 24, 193-226.

Cardich, A., Paunero, R. \& Castro, A. (1993-94). Análisis de los conjuntos líticos de la cueva 2 de Los Toldos (Santa Cruz, Argentina). Anales del Instituto de la Patagonia. Serie Ciencias Humanas, 22, 149-173.

Cattáneo, G. (2002). Una aproximación a la organización de la tecnología lítica entre los cazadores recolectores del Holoceno Medio/Pleistoceno Final en la Patagonia Austral, Argentina. Unpublished Tesis doctoral, Universidad Nacional de La Plata, La Plata.

Civalero, M. \& Franco, N. (2003). Early human occupations 
in Western Santa Cruz Province, Southernmost South America. Quaternary International, 109-110, 77-86.

Cueto, M. E. (2009). Análisis funcional de artefactos líticos tallados. Experimentos y potencialidad de una aproximación metodológica. Paper presented at the III Jornadas de Jóvenes Investigadores, FCNyM-UNLP.

Cueto, M. E. (2013). Análisis de los procesos de uso de artefactos líticos en sociedades cazadorasrecolectoras. Ocupaciones correspondientes a la transición Pleistoceno/Holoceno, Meseta Central de Santa Cruz. Unpublished Tesis doctoral. En preparación, Universidad Nacional de Buenos Aires, Buenos Aires.

Cueto, M. E. \& Castro, A. S. (2012). Technological and Functional Analysis of Pleistocene Components from La Maria Locality, Santa Cruz, Argentina. Current Research in the Pleistocene, Special, 149-163.

Durán, V. (1990). Estudio tecno-tipológico de los raspadores del sitio El Verano. Cueva 1 (Área de La Martita). Prov. de Santa Cruz. Anales de Arqueología y Etnología, 41/42, 129-163.

Ericson, J. (1984). Toward the analysis of lithic production systems. En J. Ericson \& B. Purdy (Eds.), Prehistoric quarries and lithic production (pp. 1-19). Cambridge: Cambridge University Press.

Escola, P. S. (2004). Tecnología lítica y sociedades agropastoriles tempranas. En A. Acosta, D. Loponte \& M. Ramos (Eds.), Temas de Arqueología, Análisis Lítico (pp. 59-100). Buenos Aires: Universidad Nacional de Luján.

Franco, N. V. (2004). La organización tecnológica y el uso de escalas espaciales amplias. El caso del sur y oeste de Lago Argentino. En A. Acosta, D. Loponte \& M. Ramos (Eds.), Temas de Arqueología, Análisis Lítico (pp. 101-144). Buenos Aires: Universidad Nacional de Luján.

Franco, N. V. Ambrústolo, P., Skarbun, F., Cirigliano, N., \& Marilina, M. (2011). El macizo del deseado como fuente de aprovisionamiento de rocas silíceas. Variaciones en disponibilidad y circulación: algunos ejemplos. Cazadores Recolectores del cono sur. Revista de Arqueología. Eudem, 5, 85-100.

Franco, N. V. \& Aragón, E. (2004). Variabilidad en fuentes secundarias de aprovisionamiento lítico: El caso del sur del lago Argentino (Santa Cruz, Argentina). Estudios Atacameños, 28, 71-85.

Frank, A. D. (2011). Tratamiento térmico y manejo del fuego en sociedades cazadoras-recolectoras de la Meseta Central de Santa Cruz. Unpublished Tesis doctoral,
Universidad Nacional de La Plata, La Plata.

Frank, A. D. (2012). Los fogones en la Meseta Central de Santa Cruz durante el Pleistoceno Final. Magallania, 40(1), 145-162.

Frank, A. D., Skarbun, F. \& Cueto, M. E. (2013). Caracterización de una fuente de xilópalo: el Bosque Petrificado de la Localidad Arqueológica La María. En A. Zangrando, R. Barberena, A. Gil, G. Neme, M. Giardina, L. Luna, C. Otaola, S. Paulides, L. Salgán \& A. Tivoli (Eds.), Tendencias teórico-metodológicas y casos de estudio en la arqueología de la Patagonia (pp. 379-388). Buenos Aires.

Frank, A. D., Skarbun, F. \& Paunero, M. F. (2007). Hacia una aproximación de las primeras etapas de reducción lítica en el Cañadón de la Mina, Localidad Arqueológica La María, Meseta Central de Santa Cruz, Argentina. Magallania (Punta Arenas), 35, 133-144.

Gnaedinger, S. \& Herbst, R. (2006). El género Prototaxoxylon Kräusel y Dolianiti (Taxales) de la Formación La Matilde (Jurásico Medio), Gran Bajo de San Julián, Santa Cruz, Argentina. Ameghiniana [online], 43(1), 123-138.

Guido, D., Escayola, M. \& De Barrio, R. (2006). La Formación Bajo Pobre (Jurásico) en el este del Macizo del Deseado, Patagonia: vinculación con el Grupo Bahía Laura. Revista de la Asociación Geológica Argentina, 61(2), 187-196.

Hajdas, I., Bonani, G., Moreno, P. \& Ariztegui, D. (2003). Precise radiocarbon dating of Late-Glacial cooling in mid-latitude South America. Quaternary Research 59, 70-78

Hermo, D. O. (2008). Los cambios en la circulación de las materias primas líticas en ambientes mesetarios de Patagonia. Una aproximación para la construcción de los paisajes arqueológicos de las sociedades cazadoras-recolectoras. Unpublished Tesis doctoral, Universidad Nacional de La Plata, La Plata.

Hermo, D. O., \& Magnin, L. (2012). Blade and bifacial technology in Mid-Holocene occupations at Deseado Massif, Santa Cruz Province, Argentina. Quaternary International, 256, 71-77.

Koldehoff, B. (1987). The Cahokia flake tool industry: socioeconomic implications for Late Prehistory in the Central Mississippi Valley. En J. K. Johnson \& C. A. Morrow (Eds.), The organization of core technology (pp. 151-185). Boulder: Westview Press.

Kuhn, S. (1994). A formal approach to the design and assembly of mobile toolkits. American Antiquity, 59, 426-442.

López, R. (2004). Informe Sobre Afloramientos Rocosos de Interés Arqueológico en Estancia La María, Santa Cruz. 
M.S.

Mansur-Franchomme, M. E. (1984). Préhistoire de Patagonie: l'industrie "Nivel 11" de la province de Santa Cruz (Argentine). Technologie lithique et traces d'utilisation. Oxford: British Archaeological Reports.

Matteucci, S. \& Scheinsohn, V. (2004). Procesamiento de imágenes, SIG y modelos ecológicos aplicados a la arqueología GeoFocus (Artículos), 4, 93-109

Miotti, L. (1998 [1989]). Zooarqueología de la meseta central y costa de la provincia de Santa Cruz: Un enfoque de las estrategias adaptativas aborigenes y los paleoambientes. Mendoza: Imprenta del Museo Municipal de Historia Natural de San Rafael.

Nami, H. (1992). El subsistema tecnológico de la confección de instrumentos líticos y la explotación de los recursos del ambiente: una nueva guía de aproximación. Shincal, 2, 33-53.

Nelson, M. (1991). The study of technological organization. En M. Schiffer (Ed.), Archaeological Method and Theory (Vol. 3, pp. 57-100). Tucson: University of Arizona Press.

Páez, M., Prieto, A. \& Mancini, M. (1999). Fossil pollen from Los Toldos locality: A record of the transition in the Extra-Andean Patagonia. Quaternary International 53/54 69-75.

Panza, J. (1994). Descripción de la Hoja Geológica 4969-II. Tres Cerros Escala 1:250.000. Provincia de Santa Cruz. (Vol. Boletin 213). Buenos Aires: Servicio Geológico Nacional.

Paunero, R. (2000). Localidad Arqueológica La María. En L. Miotti, R. Paunero, M. Salemme \& G. Cattáneo (Eds.), Guía de Campo de la Visita a las Localidades Arqueológicas: La Colonización del Sur de América Durante la Transición Pleistoceno/Holoceno. La Plata: Edición Nacional.

Paunero, R. (2009). La colonización humana de la meseta central de Santa Cruz durante el Pleistoceno final: indicadores arqueológicos, referentes estratigráficos y nuevas evidencias. En M. Salemme, F. Santiago, M. Alvarez, E. Piana, M. Vazquez \& M. Mansur (Eds.), Arqueología de Patagonia: una mirada desde el último confín (Vol. 1, pp. 85-100). Ushuaia: Editorial Utopías.

Paunero, R., Castro, A. \& Reyes, M. (2007). Estudios Líticos del componente medio del sitio Cueva 1 de Cerro Tres Tetas, Santa Cruz, Argentina: Implicaciones para construir patrones de distribución artefactual y uso del microespacio. En F. Morello, M. Martinic, A.
Prieto \& G. Bahamonde (Eds.), Arqueología de Fuego Patagonia. Levantando piedras, desenterrando huesos...y develando arcanos (pp. 613-622). Punta Arenas: Centro de Estudios del Cuaternario Antártico.

Paunero, R., Frank, A., Skarbun, F., Rosales, G., Zapata, G., \& Cueto, M. (2005). Arte Rupestre en Estancia La María, Meseta Central de Santa Cruz: Sectorización y contextos arqueológicos. Relaciones de la Sociedad Argentina de Antropología, XXX, 147-168.

Skarbun, F. (2009). Análisis de los conjuntos líticos del sitio La Mesada, Localidad Arqueológica La María, Meseta Central de Santa Cruz. En M. Salemme, F. Santiago, M. Álvarez, E. Piana, M. Vazquez \& M. Mansur (Eds.), Arqueología de Patagonia: una mirada desde el último confín (Vol. 2, pp. 1177-1194). Ushuaia: Editorial Utopías.

Skarbun, F. (2011). La organización tecnológica en grupos cazadores recolectores desde las ocupaciones del Pleistoceno final al Holoceno tardío, en la Meseta Central de Santa Cruz, Patagonia. Oxford: Archaeopress. Publish of British Archaeological Reports.

Skarbun, F. (2012). Variability in lithic technology strategies of early human occupations from Central Plateau of Santa Cruz, Argentina. En L. Miotti, M. Salemme, N. Flegenheimer \& T. Goebel (Eds.), Current Research in the Pleistocene. Special Edition. Southbound. Late Pleistocene Peopling of Latin America (pp. 143-148). Texas: Center for the study of the First Americans. Texas AyM University.

Skarbun, F., Cueto, M. E., Frank, A. D. \& Paunero, R. S. (2013). Producción, consumo y espacialidad en Cueva Túnel, meseta central de Santa Cruz, Argentina. Chungará, Volumen especial. Early Lithic Techologies: Beyond Regional Projectile Point Typologies, En prensa.

Skarbun, F., Frank, A. D., Cueto, M. E., Paunero, M. F., \& Rosales, G. (2007). Análisis de la tecnología lítica del Sitio Casa del Minero 1, Meseta Central de Santa Cruz. En F. Morello, A. Prieto, M. Martinic \& G. Bahamonde (Eds.), Arqueología de Fuego-Patagonia. Levantando piedras, desenterrando huesos... y develando arcanos (pp. 589-600). Punta Arenas, Chile: Centro de Estudios del Cuaternario Antártico (CEQUA).

Skarbun, F. \& Páez, G. (2012). Análisis de secciones delgadas de materias primas provenientes de la Localidad Arqueológica La María, Meseta Central de Santa Cruz, Argentina. Comechingonia. Revista de Arqueología., Número 16(Primer semestre 2012), 247-260. 
